\title{
Teaching reform and practice in Packaging Technology for the Cultivation of Innovatory Spirit and Engineering Ability
}

\author{
Ye Liu \\ Packaging Engineering Department, \\ Zhejiang Sci-Tech University \\ Hangzhou, China \\ liuyehz@163.com
}

\begin{abstract}
Based on the structural characteristics of the packaging discipline for the university personnel training objectives,this paper has made an in-depth analysis of the theoretical knowledge, curriculum content and its logical construct of the packaging process system, summed up the teaching reform research and practical experience, Specific measures to improve the theoretical system, the reform of teaching methods, teaching content and means, Provides a theoretical basis to complete the study on packaging discipline personnel training objectives, emphasis on the ability of students with quality training, improve packaging professionals the knowledge structure, cultivation of innovatory spirit and engineering ability and other aspects.
\end{abstract}

Keywords-talents cultivation, curriculum theory system, inquiry pedagogy,process approach, engineering ability, discipline construction,innovatory spirit

\section{INTRODUCTION}

Discipline construction,curriculum theory system and teaching content is the focus and difficulty of the teaching reform of higher education,it's the basic guarantee for the professional training objectives and standards of training. Packaging engineering based on the packaging and packaging engineering science, it's a comprehensive discipline professional integrated into a variety of natural and social sciences emerging and multidisciplinary integrated into a variety of natural and social sciences[1].Due to its intrinsic characteristics and the emergence and development of the environment, packaging discipline with fast development the large amount of information, multidisciplinary merging support. So, faced with the rapid development of packaging disciplines, integration and reform of related courses is urgently needed.

\section{THE COMPOSITION OF THE PACKAGING DISCIPLINE}

Packaging engineering has both natural science and social science diversity characteristics, is a multi-disciplinary, multi-professional,related ,open exchange, to create a system engineering of social.has a profound engineering content and the broad culture epitaxial [2].The composition of the packaging discipline is shown in Fig. 1.

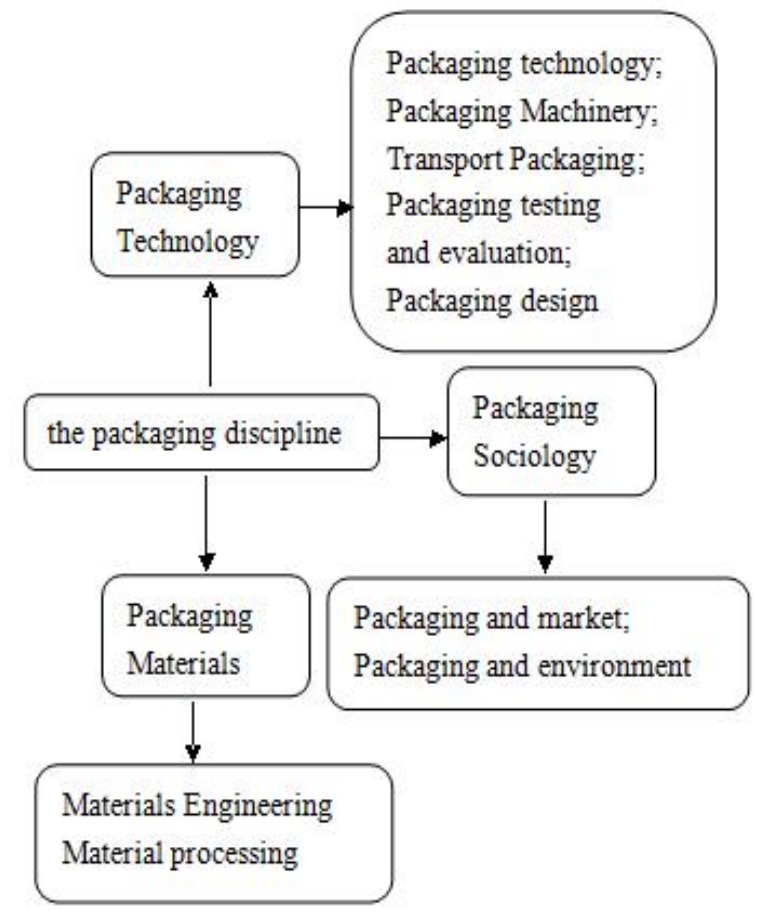

Figure 1. The composition of the packaging discipline

\section{IMPROVE THE CURRICULUM THEORY SYSTEM}

Whether they are teachers or students should not only understand the formation process, but also to pay full attention to its theoretical content and logical structure for any one of the disciplines theoretical system..

The development of packaging disciplines, information rich, disciplinary cross-widening knowledge faster and faster with the rapid development of the national economy, It's requires us to construct a reasonable theoretical system of course,to integrate the logical structure of knowledge , to meke a selection of teaching content.

Packaging technology is the main course of the packaging discipline, It's the technological sciences which is based on the protective requirements of the object to be 
packed to the corresponding. Packaging technology is applied to the packaging material or container that processed into a packaging products.its core content is the main packaging process during processing of the package.The basic theory, the basic knowledge and practical skills of these processes constitutes the packaging process knowledge system.and is closely integrated with machinery, printing, automation and other fields of knowledge [3].As the overall development of the packaging discipline, it is from scratch, from the basic theory to the application of theory,curriculum system is growing.These have been proposed increasingly serious challenges.for the limited teaching time to complete the task of teaching efficiently.

The high-speed development of the discipline and the rapid expansion of the technical have made the obsolete knowledge of the original course theoretical system to an accumulation,eliminated technology to a residue, and being derailed with the development of a modern economy and the corporate status, Therefore,we should according to the technical information development and employment environment to enrich the requirements for personnel training and to revise syllabus in the teaching plan. should take full account of the objectives and requirements of the professional training, maintain the advanced nature of the syllabus and teaching knowledge, broaden the students' knowledge, outstanding professional characteristics.

Integrate the knowledge theoretical system and the logical structure of packaging technology, add the latest developments in the theory and technical knowledge to the original system and make amendments and adjustments to Insufficient accuracy of the knowledge point, make the new curriculum system more in line with the development of modern packaging technology, enhance the logical relationship of knowledge system to fit the needs of production in order to better meet the market demand for talent.

\section{OPTIMIZATION OF TEACHING CONTENT}

Optimization of teaching content, have a role in promoting both the efficiency of the teaching and arouse the enthusiasm of learning.Through the construction of key courses and boutique course of packaging technology, carry out the reform of teaching content in addition to the emphasis on the reasonable construction of the theoretical system of knowledge. arrange various packaging process in the order from simple to complex, gradual explain or replicability, promote systematic and standardized of the packaging technology disciplines content. accelerate the the lecturing speed, improve students' ability to understand.In addition, Under the premise of complete teach basic knowledge point of the basic content, teacher should be timely to introduce discipline the most advanced packaging knowledge and provide the latest information and a wealth of information rather than limited to books, enable students to grasp the latest developments in packaging technology. abandon antiquated teaching content boldly.Use of teaching hours effective and reasonable, let students to master the most latest information in effective classroom time.

\section{REFORM OF TEACHING METHODS}

The teaching method is "On the one hand, is to organize teaching materials to adapt to the students 's psychological and demand,arouse students' interest and efforts on the other hand, to comprehend textbooks straight righteousness, and know to apply what they have learned in real life, it is method. Methods have broad and narrow, the narrowly defined, is one of the most economical means that can promote students to learn a specified things. the broad approach, it is not only to focus on learning a specified things; but also must work together to develop attitude and ability of learning things and accept things . "[4]

The teaching method is a general term of behaviour which is taken by teachers and students in the teaching process to achieve the purpose of teaching and teaching mission requirements in the teaching activities .Subordinate to the teaching methodology,consisted of the guiding ideology of teaching methods, basic methods, specific methods, teaching styles [5].The composition of the teaching methods is shown in Fig. 2.

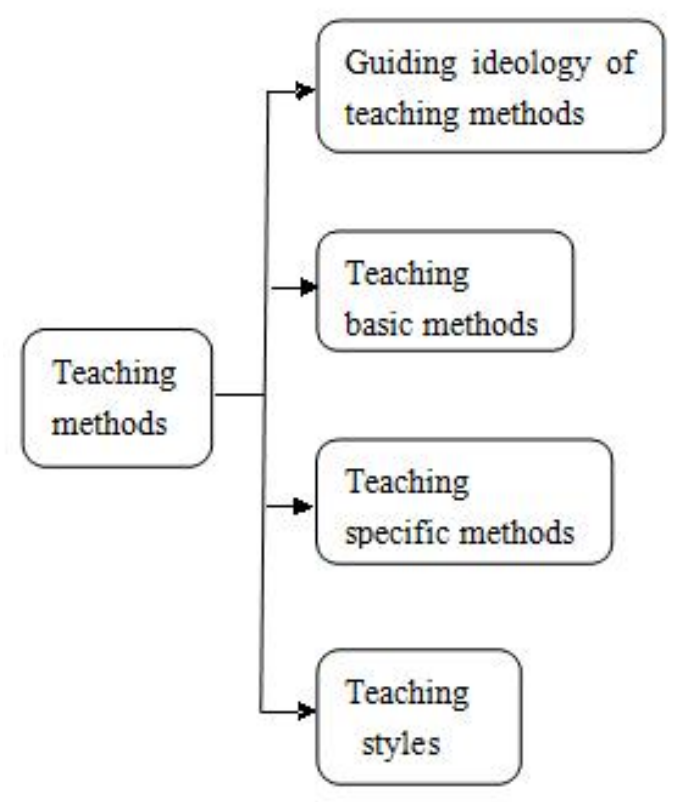

Figure 2. The composition of the teaching methods

Teaching methods include two key aspects which are the teaching methods and learning methods, it is the unity of teaching methods and learning methods. Although the shariah is in a dominant position in the teaching process, but the teaching methods must be based learning method, otherwise it would not be achieve the intended purpose effectively due to the lack of relevance and feasibility. 
Classroom teaching is one of the important aspects of teaching,reasonable method of teaching is the decisive factor in ensuring the quality of classroom teaching,can promote the tasks and goals of the curriculum to implementation smooth.In the market economy,This task and the target is to cultivate and improve students' ability based on the students to master knowledge, to make their become the required talent of social, market, enterprises.

Because of the inertia of the examination-oriented education, the majority of undergraduate students are still in the status that be in habit of "spoon-fed" teaching, They want teachers to teach them everything by hands-on approach in teaching,it is the best that the lectures same the book contents.they contradict to access to information in extracurricular; hope that teachers will provide an outline to the exam, to recite it will be able to meet the test, and even test out good results; This examination-oriented education status is very unfavorable to cultivate the ability of students,after graduating from college, they can not independently respond to and solve the practical problems in the work, it is contrary to the goals of colleges and universities training personnel.

Therefore, teachers should be to focus on students' abilities as the goal in teaching,Highlight the research on the new teaching model of teacher as the led and student as the main. reform the traditional "chalk and talk" teaching methods which is teacher speaks and students listen.

\section{A. Fully stimulate the students' thinking and learning enthusiasm}

In the teaching, teachers should use all the vivid and image of teaching methods to inspire student learning and the formation of motivation, Fully inspire the students' thinking and enthusiasm for learning; Based on the feature that the packaging technology courses require students to master knowledge system is a large, comprehensive, outstanding practicality,teachers should choose the typical knowledge section, carry out the teaching of the heuristic, the discussion-research and the learning-demonstration.guide students to master the method to learn the expertise ,then through seminars, thinking questions, review questions, etc., to urge students to a broad range of relevant disciplines and expertise, concerned about the developments of professional science and technology, take the initiative to obtain a comprehensive knowledge of packaging technology.

\section{B. Develop students' innovative potential}

For some practical course content,teachers should put innovative ideas into classroom teaching and use inquiry pedagogy,lead the students to start from the design goals,contrast artificial job status, to lead the students Image and depth into the best understanding state of structural design and process design,to develop the students' creative potential.cultivate both the logical thinking ability of design and the ability to analyze and solve problems independently,increase student interest and enthusiasm for learning content. Adoption of a process approach for new information, new technologies, new products, to mention to students in the form of a thesis, information collected by the students themselves.Process approach in teaching focus on the student's writing process,emphasized to help them to discover, analyze and solve problems in the students' writing process.guide them in each demonstration aspects such as the collection of data, analysis of information, ideas, outline, first draft, and modify,enable students to have a more indepth understanding and mastering of knowledge points in the process of writing course papers.

\section{ACKNOWLEDGMENT}

This work was financially supported by the Packaging Engineering Department, Zhejiang Sci-Tech University. Thanks for the support of the packaging process quality course project.

\section{REFERENCES}

[1] Song Baofeng, Pansy Yau. "An interdisciplinary group of new disciplines"packaging discipline. Packaging Engineering, 2001,22 (3). pp.56-57.

[2] Wang Jiamin, Wang Fangyuan. Multidisciplinary-based packaging engineering education and personnel training problem thinking . Packaging $\begin{array}{lll}\text { Engineering 2007, (9). } & \text { pp.45-48. }\end{array}$

[3] Liu Yusheng, hair red, Zhang Qin. On the packaging process for packaging engineering, architecture, science [J]. Zhuzhou Institute of Technology, (6). pp.13-15.

[4] Wang Ce. Pedagogy is issued [M]. Beijing: People's Education Press. $1985 . \quad$ pp.244 248. [5] Baidu Encyclopedia,the teaching baike.baidu.com/view/424858.htm, 2010-12-31.

[6] Baidu Encyclopedia,teaching methods,baike.baidu.com/view/70668 4 .htm, 2010-12-27.

[7] Chen Baolin. Exploration and Consideration of Packaging Engineering Education . Packaging Engineering, 2003, (4).pp.83. 